\title{
A CRIANÇA E SUAS NARRATIVAS: A (AUTO) BIOGRAFIA NO ESPELHO
}

\section{SANDRA MAIA-VASCONCELOS}

Universidade Federal do Ceará

RESUMO Os estudos sobre narrativas produzidas por crianças ainda são incipientes, no campo da Linguística, embora já encontrem uma efetiva difusão nas áreas da Sociologia, da Psicologia e da Pedagogia. Nossa pesquisa pretendeu contribuir com a ciência, trazendo para o campo da Linguística essa abordagem que pode apoiar a formação docente, nas áreas de línguas, em particular no ensino da língua materna, quando busca, pela valorização da criação verbal, entreter uma relação entre o universo lexical da criança e sua disposição à descoberta da narrativa, como gênero de intuito criador É importante que ressaltemos o que vêm a ser narrativas infantis: ora, nós precisaremos narrativas infantis como sendo narrativas contadas por crianças, histórias narradas por crianças; ora, histórias contadas para crianças por algum adulto presente; ora, histórias universais criadas para o público infantil em geral. Deste modo, diferenciaremos narrativas infantis como histórias universais contadas para crianças, e as histórias narradas pelas crianças, como sendo suas histórias, serão as narrativas das crianças, suas próprias vidas ou adaptações que elas fazem de suas próprias vidas, a partir de histórias populares, ficcionais ou não. Para esse intuito, traremos à tona os detalhes que as crianças elaboram em seus discursos narrados, incluindo o imperfeito lúdico, nas narrativas tradicionais, e retomadas intuitivamente pelas crianças.

Palavras-chave: Narrativas infantis. História de vida. Autorreflexividade.

\section{ABSTRACT CHILD AND NARRATIVE: A (AUTO)BIOGRAPHY IN THE MIRROR}

Studies of narratives produced by children are still incipient in the field of Linguistics, although already on effective dissemination in the areas of Sociology, Psychology and Pedagogy. Our research sought to contribute to science by bringing to the field of Linguistics this approach that can support teacher formation in the areas of langua- 
ges, particularly in the teaching of native languages, when it seeks, for the valorization of the verbal creation, entertain a relationship between child lexical universe and its motivation to the discovery of the narrative as a genre of creative order. It is important that we emphasize what we understand as children's narratives: sometimes we define children's narratives as stories told by children, sometimes as stories told to children by an adult, and sometimes as universal stories created for children in general. Thus, we differentiate children's narratives as universal stories created for children and stories narrated by children as their stories, their own lives or adaptations they make of their own lives from popular stories, fictional or not. To this end, we will bring to light the details children elaborate on their narrated speeches, including the playful imperfect in traditional narratives and intuitively taken over by children.

Keywords: Children's Narratives. History of Life. Self-reflexivity.

Los estudios de las narrativas producidas porniños son aún incipientes en el campo de la lingüística, aunque ya haya una difusión efectiva en las áreas de sociología, psicología y pedagogía. Nuestra investigación pretendía contribuir a la ciencia, y traer al campo de la Lingüística un enfoque que puede apoyar la formación de maestros en el área de lengua, sobre todo en la enseñanza de la lengua materna, en la búsqueda de la apreciación de la creación verbal, teje una relación entre el universo lexical del niño y su disposición para el descubrimiento de la narrativa como género de fin creador. Es importante que resaltemos lo que vienen a ser las narrativas infantiles: ora, precisaremos narrativas infantiles como siendo narrativas contadas por niños, historias narradas por niños; ora, historias contadas para cniños por algún adulto presente; ora, historias universales creadas para el público infantil en general. De este modo, diferenciaremos narrativas infantles como historias universales contadas para niños, y las historias narradas por los niños, como siendo sus historias, serán las narrativas de los niños, sus propias vidas o adaptaciones que ellos hacen de sus propias vidas, a partir de historias populares, ficcionales o no. Para ese fin, traeremos los detalles que los niños elaboran en sus discursos narrados, incluyendo el imperfecto lúdico, en las narrativas tradicionales, y retomadas intuitivamente por los niños.

Palabras clave: Narrativas de niños. Historia de vida. La auto-reflexividad.Primeiros reflexos 
Antes de dar início à narrativa desta pesquisa, eu me sinto no dever de explicar seu título, em especial o subtítulo: a (auto)biografia no espelho. Por que o espelho? Há muitas formas de interpretação e aqui me deterei em apenas uma delas: quando uma criança se vê pela primeira vez em um espelho, o que ela vê é uma outra criança; somente por volta dos dois anos de idade é que a criança passa a perceber que aquela imagem é dela mesma. É o momento em que ela vai experienciar suas várias feições, caretas, existências. Interessa-nos pensar nesta primeira imagem, de reflexão ricoeuriana (RICOEUR, 1990): si mesmo como um outro, para compreender quem é si. Daí por que aqui tratamos de primeiros reflexos...

A quem pertence uma experiência de vida? A experiência pertence a quem a discursiviza? O caso da experiência herdada seria exemplar disso? De que caminhos são feitos os atalhos para se chegar à história contada de alguém? São necessariamente atalhos? Não sei por que questionei essa escolha, mas essa projeção de si, que desemboca numa história contida, me parece mais um longo caminho, sinuoso e complexo, cheio de encruzilhadas, do que a sorte de encontrar um atalho. Questões singulares como estas sempre nos tocam, como interesses de pesquisa, e sempre nos deixam em meio a uma passagem estreita entre o conhecimento e o segredo. Quando e em que circunstância podemos circular com a caneta do destino uma experiência e denominá-la vivência? Seriam sinônimos estes conceitos? Seriam vizinhos?

\section{Autorreflexividade em narrativas infantis: me conta minha história...}

Retomamos a questão que incita essa discussão oriunda de minha pesquisa de pós-doutoramento: por que estudar biografias? 0 que pode haver de enriquecedor, do ponto de vista acadêmico, numa narrativa pessoal, num diário íntimo ou em histórias contadas por pessoas comuns, sem nenhum estatuto de pessoa histórica, sem nenhum cargo decisivo para a história das cidades, dos países ou do planeta? Os grandes narradores de histórias de vida também ficaram célebres por narrarem histórias de grandes personagens. Mas e o agricultor, o canavieiro, o motorista de táxi, a enfermeira do posto, o gari, a vendedora da lanchonete - são pessoas importantes e merecedoras de terem suas vidas contadas? Que dizer das crianças? As crianças têm história?

Interessamo-nos por abordar as narrativas que as crianças contam e, nisso, gostaríamos de chamar a atenção para a estrutura e a natureza social dessas narrativas, uma vez que consideramos a contação de histórias como um fenômeno, hoje social, uma prática pedagógica que ganha espaço nas escolas e em múltiplos ambientes.

Este estudo ${ }^{1}$ se realizou em três ciclos investigativos: 1 - provocações discursivas e reflexivas, com apoio em livros e filmes, junto às crianças alojadas na Casa de Apoio à Criança com Câncer Lar Amigos de Jesus; 2 - formulário SURVIO on-line; 3 - histórias do cotidiano. No primeiro momento, o contato com as crianças foi direto e duradouro, oportunidade em que foi possivel ouvi-las diretamente e observar suas estratégias de escolha de argumentos para a definição da atividade proposta. No segundo momento, por meio do formulário eletrônico, entram os adultos e suas percepções sobre a infância - sua e do outro. No terceiro momento, as histórias ocorridas ou criadas por e com crianças, presenciadas ou contadas por um adulto, mas que advêm de uma ou mais

1 Pós-doutoramento realizado na Universidade $\mathrm{Fe}$ deral do Rio Grande do Norte, sob a supervisão de Conceição Passeggi, no âmbito do projeto de pesquisa "Narrativas da infância: o que contam as crianças sobre a escola e os professores sobre a infância" (MICT-CNPqIEditalUniversal-14/2014, processo no 462119/2014-9). 
crianças, numa situação espontânea. Para este trabalho, fizemos um recorte e deixamos apenas as perspectivas das crianças, não incluindo aqui as respostas dos adultos.

\section{Descrição da pesquisa e análise dos dados}

Os estudos sobre narrativas produzidas por crianças ainda são incipientes no campo da Linguística, embora já encontrem uma efetiva difusão nas áreas da Sociologia, da Psicologia e da Pedagogia. Nossa pesquisa pretende contribuir com a ciência, trazendo para o campo da Linguística essa abordagem que pode servir de apoio à formação docente, nas áreas de línguas, em particular no ensino da língua materna, quando busca, pela valorização da criação verbal, entreter uma relação entre o universo lexical da criança e sua disposição à descoberta da narrativa, como gênero de intuito criador. Nosso corpora é extenso, porque buscamos alcançar variados domínios de produção narrativa, em suportes multimodais (criação oral, criação escrita, redes sociais - Facebook, Whatsapp, vídeos do Youtube, além de diálogos informais), em nossa pesquisa, que servirão de base à produção futura de trabalhos de mestrandos e doutorandos, conforme já estamos realizando. Por esta razão, o recorte foi pensado para maior aprofundamento desse momento de estudo.

Nossos objetivos de estudo foram: 1 - estudar narrativas infantis, tendo como corpus as narrativas que as crianças contam e que marcam todo o período da infância; 2 - analisar a construção do efeito de realidade nas narrativas infantis; 3 - avaliar as construções narrativas de crianças em situação de retomada de histórias, levando em conta seu ponto de vista e sua responsabilidade enunciativa; 4 - identificar sinais de reflexividade, indicadores de uma narrativa de si, presentes na reconstrução das histórias retomadas.

É importante que ressaltemos o que consideraremos ser narrativas infantis: ora, nós precisaremos narrativas infantis como sendo narrativas contadas por crianças, histórias narradas por crianças; ora, histórias contadas para crianças por algum adulto presente; e ora histórias universais criadas para o público infantil em geral. Deste modo, diferenciaremos narrativas infantis como histórias universais contadas para crianças, e as histórias narradas pelas crianças, como sendo suas histórias, serão as narrativas das crianças, suas próprias vidas ou adaptações que elas fazem de suas próprias vidas, a partir de histórias populares, ficcionais ou não. Para esse intuito, traremos à tona as precisões de detalhes que as crianças elaboram em seus discursos narrados. Interessamo-nos por abordar as narrativas que as crianças contam e, nisso, gostaríamos de chamar a atenção para a estrutura e a natureza social dessas narrativas, uma vez que consideramos a contação de histórias como um fenômeno hoje social, uma prática pedagógica que ganha espaço nas escolas e em múltiplos ambientes.

Alain Rabatel (2008) vem trabalhando com o aporte teórico dos conceitos de responsabilidade enunciativa e de ponto de vista, que nos interessam aqui, entretanto o autor ainda não abordou as narrativas de crianças, o que tentamos organizar neste estudo, levando em conta que a reflexividade do adulto sobre a criança, que representa o outro, e a criança que este adulto foi um dia são dois polos diferentes, sem, no entanto, deixarem de ser ambos relevantes para nosso estudo. A relevância que buscamos apresentar para os estudos discursivos da linguagem é a configuração de uma proposta de modelização da relação de reflexividade e ponto de vista, em histórias contadas por crianças, tendo como foco o modo como o adulto, assumindo discursivamente sua pró- 
pria infância, compreende a infância do outro.

Para Hans Jonas (1997), a noção de responsabilidade abrange uma perspectiva de amplitude máxima e social. Jonas defende que a responsabilidade da humanidade ultrapassa largamente as capacidades de ação do indivíduo. Nas palavras do autor, “[...] A responsabilidade como tal não é outra coisa senão o complemento moral da nossa constituição ontológica, do nosso ser temporal" (JONAS, 1997, s.p.).

Quando tomamos os dois conceitos, compreendemos o que afasta o adulto da criança que um dia ele foi. A constituição ontológica do ser, de que nos fala Jonas, ao longo do tempo, possibilita essa compreensão. Não somente abordada em pesquisas envolvendo questões sociais, foco de estudo de Jonas, mas, nos domínios da linguagem, essa constituição é plausível. Rabatel (2008) ordena um estudo em que é admissivel a compreensão de que responsabilizar-se é tomar para si e assumir os atributos de um fato ou de um objeto, compreendendo aquilo que se assume como responsabilidade e como verdade. Assim, podemos compreender, por extensão de sentidos, que a responsabilidade enunciativa é um fenômeno que resulta do princípio de sinceridade, pois é necessário que o enunciador se engaje no discurso, assumindo um determinado ponto de vista.

Culioli (apud PASSEGGI et al., 2010) defende que "toda enunciação supõe a responsabilidade enunciativa do enunciado por um enunciador" (2010, p. 153). Diante de tal afirmação, começamos a nos indagar se esta responsabilidade também é assumida pelas crianças, quando narram as histórias por elas conhecidas ou inventadas. Sendo assim, (re)contar uma história, tomando por base a alegação do pouco conhecimento de mundo que as crianças possuem, é apresentar um ponto de vista, mas será necessariamente assumir a responsabilidade pelo contado? Certo, a cada fala nossa estamos pondo às claras o que queremos aventurar como nosso pensamento; muitos trabalhos sobre ethos vêm discutindo estas questões. Questionamo-nos, então, se, do mesmo modo, quando um adulto fala da criança que ele mesmo foi ou da criança com quem ele teve contato, esse adulto assume uma posição fixa, irredutível?

Ao longo de nosso estudo, muitas questões surgiram, algumas tratamos de já trabalhar neste documento, outras deixamos para uma exploração futura. No entanto, as percepções do adulto sobre as histórias de crianças foram muito importantes para nossas reflexões. Em outro momento, voltaremos a tratar da opinião dos adultos sobre as histórias infantis.

Rabatel (2008) afirma que uma das ferramentas que pode auxiliar na análise de um texto é a problemática do ponto de vista, tema que trataremos apenas superficialmente, vez que não se trata de nosso objetivo. Assim, observamos que o adulto, ao tratar da criança que ele foi, discursiviza não somente sua história, mas a história de uma criança ideal. Nesse momento, e para a pesquisa, havemos de considerar que o sujeito que se expressa, quer singular, quer coletivo, constitui um foco idealizado: essa criança ideal de que o sujeito trata ultrapassa o domínio do real e da experiência, o que nos permite antecipar a tese de que o si é sempre como se fosse si.

Para Dilthey (2010b), o "ponto de vista individual, que se prende à experiência pessoal de vida, retifica e se amplia na experiência geral de vida". Compreendemos que essa experiência geral de vida tenha estreita relação com o cotidiano, com o coletivo, indique o modus vivendi de uma comunidade, levando em conta que cada comunidade fará uma parte de um todo social que, por sua vez, terá suas experiências magistrais, universais. São princípios diretores de experiências comuns que se formalizam por meio de enunciados que narram 
o percurso - ou o transcurso, tal qual nos infere Dilthey (2010b) - de uma vida, suas normas, seus juízos de valor. A discursivização da vida é uma linha que permeia histórias de multiplicadas conformações cotidianas, que se alternam, formando um conjunto a que se dará o nome de comunidade. Para Dilthey (2010b), as verdades ou juízos em história de vida são generalizações que não obedecem à chamada validade científica, uma vez que não existe, a despeito das leis que regem um país, uma metodologia de vida que nos leve a enunciar nossas histórias por meio de fórmulas fixas. ${ }^{2}$ Por esta razão, nos diz este autor, embora todas as experiências digam respeito tanto ao homem singular quanto à vida em sociedade, é inegável a "incontrolabilidade do surgimento de seu saber sobre a vida" (DILTHEY, 2010b, p. 92). É no mundo e com o mundo que o indivíduo, seja ele singular ou plural, compreende os demais e onde suas manifestações se realizam.

Essa postura de Dilthey (2010b) também se observará bem mais tarde na posição teórica de Bourdieu (1996), magistralmente discutida por Passeggi (2014), em artigo que subleva Bourdieu à transição de uma revolução biográfica. Passeggi discute, nesse trabalho, acerca dos posicionamentos epistemológicos de Bourdieu, ao longo de sua vida, o rico debate entre os posicionamentos teóricos de Ferrarotti e Dominicé. A partir dessas reflexões de Passeggi (2014) acerca da (r)evolução dos estudos biográficos como ciência, podemos nos embrenhar na perspectiva infantil, de reflexões e narrativas de si elaboradas por crianças, levantando a hipótese de que as crianças desenvolvem posicionamentos vivenciais, a

2 SIQUEIRA (2014) analisou Boletins de Ocorrência em Delegacia da Mulher e constatou que, apesar do modelo fixo de documento e das motivações de denúncias, as histórias são diferenciadas. Conf. SIQUEIRA, Karina Aragão de. Ortodoxia e heterodoxia nos relatos de mulheres vítimas de violência conjugal: amar a si mesmo como ao próximo. 2014. 167f. Tese (Doutorado em Doutorado em Linguística) - Universidade Federal do Ceará, Fortaleza, 2014. partir de suas próprias experiências.

A criança não foge a esse esquema compreensível de mundo, pois é capaz, desde cedo, de compreender e de empreender enunciados que circulam no meio em que se insere como indivíduo. A criança nasce, cresce e se desenvolve em um meio de cujas regras e normas ela também partilhará. Concordamos com Dilthey (2010b) acerca da ideia de que a criança muito antes de aprender a falar já compreende o mundo onde vive, por movimentos, por olhares, por posturas que ela sabe dever adotar para que se oriente de maneira objetiva dentro do ambiente social em que vive. Dilthey (2010b) denominou essa capacidade de compreensão elementar. Essa analogia implica, a nosso ver, compreender que a criança, ainda que muito jovem, já percebe que existe um elemento comum de comunicação, que ela precisa dominar, para que possa ser compreendida e atendida em suas demandas, em sua comunidade linguística, elemento que especifica o significado das palavras, as formas flexionadas, a sintaxe em sua articulação, bem como as expressões que instrumentalizam sua comunicação plausivel na dita comunidade.

Dilthey (2010b) denominou de formas superiores de compreensão a interpretação dos adultos acerca de suas experiências. Para este autor, quanto mais distanciados estamos da realidade de que tratamos, mais tentamos apagá-la de nossa memória, e mesmo tentamos suprimi-la, seja por um disfarce discursivo, seja pelo silêncio decorrente do medo de que o outro nos descubra como tal somos. Rabatel (2008) propõe um estudo complexo sobre as diferentes assunções de responsabilidade sobre o autodiscurso: o levar em conta, a imputação, a concordância e a discordância, e ainda a falta de engajamento, ou seja, a rara e delicada posição de neutralidade, que, a meu ver, não existe. Muitas vezes, o outro não se exime de elaborar uma compreensão sobre 
nossas atitudes e mesmo erroneamente o faz: interpreta-nos a partir de expressões faciais, manifestações fisicas, atitudes de fuga, levando-nos frequentemente a elaborar enunciados corretivos dos juízos de valor atribuídos a nós, a nosso si, confirmando nossa tese de que este si é sempre como se fosse si.

Destarte podemos atrelar a circunstancialidade da vida ao que tenho chamado disposição linguageira, que encenamos no cotidiano, obviamente sem ousarmos aqui explicitar verdades absolutas sobre modo vivendi ou modo loquendi. A vida é encenada e dirigida para as conexões com o mundo, por meio de recursos e mecanismos linguísticos aos quais somos expostos desde nosso nascimento e aos quais acrescentaremos nossos próprios comandos, ao longo da vida, por imitação ou por intuição. Assim como numa apresentação de teatro, conforme sugere Dilthey (2010b), os espectadores - letrados ou não - vivem o que a peça lhes oferece sem pensar na autoria da peça, pois vamos organizando os encantos e os desencantos do cotidiano, sem nos associarmos - salvo por momentos de lucidez extrema, em que encarnamos uma metapessoa em nós - como autores dessas circunstâncias. Esse momento acontece na escrita de si, quando, narrando a própria experiência, o si chega mais perto do próprio si, formulando um contraponto importante de nossa tese, pelo tangenciamento plausivel dos autodiscursos.

Uma vez a ideia de narrativa presente em nosso cotidiano, representada seja por linguagem oral ou escrita - fundamentais em nosso estudo -, seja por imagens, gestos, enfim, por uma pluralidade de formas pelas quais a narrativa pode ser concebida, ela desempenha a função de comunicação, não somente entre os indivíduos, mas também entre seus lugares, suas histórias, suas vivências, suas memórias e as memórias que lhes fizeram adquirir, ao longo do tempo; eis por que o contar se torna tão importante. As histórias nem sempre são criadas por quem conta, tampouco são vividas tais como são contadas. Muitos de nós somos capazes de rememorar fatos que na verdade não estão no nosso circuito de lembranças, por não havermos vivido tais acontecimentos; porém, ao longo da vida, nos vão contando histórias que se fundem com nossas próprias histórias, promovendo um misto de informações que não seríamos capazes de distinguir, se advindas de vivência realmente ou se construídas em nossa memória como uma lembrança emprestada que, de tanto ouvirmos falar, já se transportou para nossa percepção como se fosse nossa. Quem nunca contou uma história e jura ter passado e ter vivido aquela situação, mesmo sabendo que talvez seja impossivel de ter acontecido, pois ou foi há muito tempo, ou não foi consigo e sim com seu irmão? Mas nos foi contada de tal maneira que somos capazes de vivenciá-la, novamente, e senti-la como se tivesse acontecido há poucos dias. E revivenciá-la sem jamais tê-la vivido de fato. Quando cria uma mentira, por exemplo, um adulto pode se tornar escravo de tal relato e passar a transformá-lo numa verdade que nem mesmo ele será capaz de refutar, com o passar do tempo.

Sobre essa percepção do como se fosse verdadeiro, remetemo-nos a Schopenhauer (2009) e suas ideias sobre o mundo e sua representação pela vontade. Desse modo, podemos entender este processo de pensar a narrativa de crianças como a impossível decifração discursiva de que nos fala François et al (1984) que afirma ser impossivel saber no que o discurso se transformará no ouvido, na digestão do outro. Ainda dentro das ideias de François (2004), ressaltamos a possibilidade de compreensão do que seja estar no "genérico-particular" de maneira explícita nos textos produzidos por crianças, vez que a espontaneidade infantil estabelece este processo natural de saber 0 
que diz e o que o outro deve saber sobre o que ela diz. Isso implica um genérico-particular, pois os aspectos mais gerais para o produtor do texto tornam-se também, por meio de seu ponto de vista, a compreensão do outro.

O tempo narrado não é necessariamente um tempo vivido, mas muito frequentemente o tempo visto de longe. Os sujeitos que narram recontam um passado recente, mas em um contexto muito distante do que eles viveram. As distâncias marcam-se tanto no sentido quanto no tempo, e até mesmo no espaço. 0 confronto entre passado e presente forma uma memória intermediária, como nos afirma Barthes (1984, p. 176) "Je suis moi-même mon propre symbole, je suis l'histoire qui m'arrive: en roue libre dans le langage, je n'ai rien à quoi me comparer [...]".3 Também é bem possivel que estas crianças não percebam o passar do tempo, embora o contexto muitas vezes lhes faça perderem os rastros (MAIA-VASCONCELOS, 2010).

O tempo da narração é, por outro lado, um tempo em que a possibilidade de se recuperar parece possivel. 0 momento do conflito marcado pela prototipia é dificil de enfrentar, porque as informações são expostas sem lacunas. No presente estudo, a narração oral das crianças do abrigo é feita ao tempo mesmo da crise e na evolução da doença, mas não imediatamente após o diagnóstico. Elas tiveram o tempo de enfrentar a nova situação, de tomar decisões, conhecer a rotina hospitalar, o sofrimento trazido pela nova realidade. Deixo-lhes tempo para amadurecer a ideia da doença. A análise destina-se a priorizar as palavras das crianças, por isso decidimos que as narrativas selecionadas tinham a mesma condição de importância para a pesquisa.

3 Eu sou eu mesmo meu próprio símbolo, eu sou a história que me acontece: na roda viva da linguagem, não tenho com o que me comparar.

\section{A linha mestra da pesquisa}

Muito se trata de perscrutar a linguagem da criança, nos aspectos de aquisição e desenvolvimento, mas os sentidos que esse sujeito constrói de sua linguagem ainda é estudado de maneira incipiente. Desta feita, e tendo como finalidade inserirmo-nos na hermenêutica do pensamento infantil, e de como, a partir de si mesmo - o que consideramos reflexividade -, esse sujeito constrói sua significação de mundo, fomos buscar em Dilthey (2010a) as bases de nossas discussões, levando em conta sua tese de "compreensão" enquanto apreensão de sentido, já brevemente citada aqui.

Dilthey (2010a) continuou os estudos hermenêuticos de Schleiermacher (1999), pontuando, contudo, sua teoria sobre o aspecto psicológico da compreensão das expressões e das criações culturais vistas como compreensão da vida mental nelas expressa. Para Dilthey (2010a), no entanto, a elaboração do problema é muito mais abrangente, dada a necessidade de suplantar as elucidações psicológicas, atomistas e associacionistas, por uma compreensão da vida em suas estruturas complexas de sentido. Para seu seguidor Heidegger: "A sua importância filosófica reside no fato de ele estar a caminho da questão da vida" (2002, p. 83). Contrariando os estudos de Kant, Dilthey (2010a) defende que não há crítica da razão sem um apoio histórico, vivencial e interpretativo. Não há, tampouco, nenhum retorno do espírito objetivo sobre si mesmo para a efetivação de um espírito absoluto, o espírito é sempre histórico e, portanto, relativo (SÁ, 2009, p. 38). Parece que vemos aqui o princípio da espiral hermenêutica: o individual entende-se pelo todo, e o todo pelo individual.

É importante lembrar, no entanto, que a hermenêutica não é um conhecimento recente, conforme nos lembra Luna (2010), pois as discussões remontam às proposições filosóficas dos antigos gregos (Hermes). Trata-se, na ver- 
dade, de uma releitura de proposições históricas - que vêm desde a antiga Grécia, incidindo nas discussões sobre a interpretação dos textos cristãos até na época do Renascimento, momento em que se instituem três princípios fundamentais de representação: "sacra", "profana" e "júris" - que tomam essencialmente os campos de discussão da linguagem, na religião, na filosofia e nas ciências jurídicas. No século XIX, a Alemanha nos apresentará o filólogo e filósofo Friedrich Schleiermacher como um pioneiro a discutir sobre a hermenêutica na obra Hermenêutica e crítica [Hermeneutik und Kritik], de 1838. Segundo Luna (2010, p. 210), Schleiermacher (1999) considerava a hermenêutica um método verdadeiramente eficaz de interpretação - de apreensão de sentido - que apoia na dialética sua crítica inicial, tomando como princípio a reflexão "sobre as relações entre o universal e o particular".

O método de interpretação alvitrado por Schleiermacher (1999), que romanticamente condiciona "toda produção de expressão humana como situada em um horizonte linguístico" (LUNA, 2010, p. 209), dedica-se a esquadrinhar sentidos a partir da interpretação textual, levando em consideração, na leitura, igualmente a inseparabilidade entre o sujeito (autor) e objeto (obra). Para Schleiermacher (1999), o progresso de uma prática considerada hermenêutica - envolvendo as noções crítica, teórica e filosófica - constituiria a capacidade de restabelecer os princípios gerais de toda e qualquer leitura e compreensão das manifestações da linguagem, enxergando na hermenêutica uma metodologia e uma arte estética, ou seja, um estudo de dimensão sobre as formas e sentidos, sobretudo a questão de como o homem se manifesta e é lido em aparência - de sentidos do texto escrito (LUNA, 2010, p. 211).

Muitas foram as contribuições de Schleiermacher (1999) para o aperfeiçoamento e a uti- lização prática do pensamento hermenêutico nas Ciências Sociais, mais tarde refletidas sobre as Ciências Humanas, por Dilthey (2010a8). Podemos destacar as discussões profícuas e convenientes reflexões sobre a circularidade interpretativa que se pode flagrar entre o todo e o particular da escrita. Para o filósofo, é notória, quiçá indiscutível, a dependência textual constitutiva entre a parte e a totalidade, o que nos colige a rejeitar a tese de que seja possível haver "compreensão" por mera indução. Também é importante ressaltar das ideias de Schleiermacher (1999) a compreensão de que, por intermédio da relação vislumbrada entre a dialética e a hermenêutica, é possivel interpretar que o homem, em sua manifesta experiência, nunca conhece a "coisa em si", a realidade é irreal, uma vez que o homem estetiza as coisas, com uma capacidade de subjetividade singular e simbólica, aquilo a que o filósofo nomeou uma "poética", como complemento da razão, e a que chamamos ethos, engendrado socialmente.

Daí por que Schleiermacher (1999) vem defender a "inseparabilidade entre o pensamento e linguagem", tema mais tarde discutido por Vigotsky (1998) e Piaget (1999), por meio de inumeráveis reflexões que expõem uma múltipla relatividade de pontos de vista. Em outras palavras, o filósofo alemão vem nos mostrar o caráter inexequível e inexplorável da existência de uma linguagem universal, defendida arduamente pelos gerativistas no século XX. Schleiermacher (1999) chama a atenção dos pesquisadores que ambicionam se utilizar da hermenêutica, como técnica ou teoria da interpretação, em seus caminhos científicos, para que conheçam antes os gêneros narrativos, antes mesmo de encetar tal obstinação escrita.

E é se apoderando da linguagem, como o melhor manancial de relatividade do pensamento, que Schleiermacher sugere que "a 
compreensão avança na medida em que se comparam textos pesquisados e encontram divergências que indiquem possibilidades de diferentes leituras" (SCHLEIERMACHER, 1999, p. 105). Graças às leituras realizadas das obras de Schleiermacher (1999), Dilthey (2010a) começou a se debruçar sobre as questões envolvendo linguagem e pensamento e investiu-se a reformular os conceitos metodológicos advindos da hermenêutica, tornando-os legítimos e "seriamente utilizáveis para o campo das 'ciências humanas"' (LUNA, 2010), constituindo-se como "legítimas ciências empíricas"”. As reflexões de Dilthey (2010a) induzirão a historicidade do sujeito como delimitadora da objetividade do conhecimento histórico. Não há sujeito sem história, nem há história sem sujeito, do mesmo modo que, como defendia Aristóteles ((apud BERGSON, 2013), não há lugar nem antes nem sem as pessoas.

Nessa linha de pensamento, que insere o homem no centro de toda e qualquer perspectiva histórica, Dilthey (2010a) inclui no âmago da compreensão de mundo a narrativa desse mundo, fator humano inegável. Dilthey, em sua obra "A construção do mundo histórico nas ciências humanas", originalmente publicada em 1883, vem tratar da estrutura das ciências humanas e sobre a influência que as ciências naturais têm sobre estas. Neste ponto, é-nos mister lembrar o quanto Dilthey (2010a) traz à tona a estreita relação entre a vida, a experiência de vida e a formação biográfica, em especial a biografia social. Para Dilthey (2010a), a "dimensão poética" da linguagem é característica dos homens, uma vez que os diferentes enunciados sobre a realidade, sobre os desejos, são expressões da linguagem "sobre a qual repousam valorações" (DILTHEY, 2010a, p. 93).

É-nos, desse modo, muito fecunda a percepção de Dilthey (2010a) sobre os estudos em ciências humanas (Geisteswissenschaften), ao considerar este autor que não há possibilida- de de se separar a dimensão poética da histórica e da vida, na produção do conhecimento. A experiência humana é, de fato, um suporte para se alcançar a objetividade do conhecimento das também chamadas ciências do espírito. Esquadrinhando aquilo a que chamou "sentido textual", Dilthey (2010b) interroga não só sobre a escrita de um sujeito-autor, mas também sobre sua vida, concebendo a inserção da perspectiva metodológica hermenêutica na esfera das ciências sociais, não apenas no domínio da linguagem, tal como tratou Schleiermacher (1999), de teor individual; incluiu neste domínio a sociedade, a vida e os atores sociais. Tomar a hermenêutica já proposta por Schleiermacher (1999) como modelo metodológico induz a compreensão da circularidade da ciência proposta por este autor e retrabalhada por Dilthey (2010b) na concepção de giro hermenêutico, mais tarde retomada por Ricoeur (1991), de que a compreensão é subordinada ao sentido e o sentido só se constrói pela compreensão.

Como defende Dilthey:

As vivências estão ligadas umas às outras em uma unidade de vida no transcurso do tempo; cada uma delas tem, assim, a sua posição em um transcurso, cujos elos estão ligados uns aos outros na lembrança. (DILTHEY, [1883] 2010a, p. 93)

Em seus estudos sobre crianças autistas, Cruz et al (2010) encontraram uma brecha na perturbação da comunicação comum ao autismo: as crianças planejam sua comunicação e, relativamente à fala, estabelecem uma conversa sem problemas. Trazemos aqui este exemplo para ilustrar que as crianças são capazes de estabelecer seus vínculos comunicacionais, mesmo quando sua condição neurológica é comprometida. Os autores afirmam que os autistas conseguem compreender quando se propõe uma brincadeira e até mesmo quando se decide mudar de brincadeira, desde que thes seja explicado o motivo da mudança. 
Os estudos de Cruz et al (2010) nos são úteis por inserirem um comparativo ao fenômeno do conflito frequente entre crianças, os jogos de posse e de afirmação do eu. Defendemos a afirmativa de que este eu traduzido em si, como um projeto de si, traz consigo sempre a concepção de uma possibilidade de um si, si mesmo como se fosse si. Vemos nas histórias espontâneas ou provocadas que o fenômeno se repete. Aquilo que é proposto por si mesmo se torna acessivel ao outro, por intermédio de uma produção de representações externas, como uma nota musical, um texto ou uma expressão física qualquer. Essas manifestações são patentes de um transcurso linguístico, que se engloba frente ao tempo de manifestação. Para Dilthey, o

[...] mundo é o meio, no qual a compreensão de outras pessoas e de suas manifestações vitais se realiza [...] tudo em que o espírito se objetivou contém em si algo comum ao eu e ao tu [...]. (DILTHEY, 2010a, p. 189)

E foi interessante perceber essa consciência do outro nas atividades com as crianças.

Pineau e Le Grand (1996) consideram as histórias de vida como uma ponte entre a história e a vida, empreendida como tempo e subjetividade. A construção do sentido encontra-se nesse hiato existente entre os dois lugares em que se cruzam as emoções e as horas, em que o sujeito toma lugar também de objeto, em busca da vida. Os autores trazem à tona os fatores "palpáveis e visiveis" das expressões dos récits de vie, que consideraremos aqui, a partir da oralidade das crianças narradoras.

Os autores dão atenção especial aos seguintes fatores, que se enquadram ao ato narrativo: o objeto da expressão, a vida, rica de significado e por essa razão interessante de trabalhar, mas não tão fácil; os objetivos, divididos pelos autores em três categorias: comunicação social, conhecimento de si ou do outro e autopoiese. Finalmente, a temporali- dade, dividida pelos autores em dois momentos: o tempo passado (curto - médio - longo) e o tempo presente da narração (PINEAU; LE GRAND; 1996).

Atrelamos esses três fatores, organizados por Pineau e Le Grand (1996) à conceptualização de Havelock (1995 apud MACEDO, 2004) acerca da oralidade. Havelock defende a efetividade da prioridade da oralidade sobre a escrita. Conforme explica Macedo (2004, p. 32), Havelock fundamenta-se no caráter histórico, para defender a primazia do oral sobre o escrito, uma vez que "as sociedades com cultura escrita surgiram a partir de grupos sociais com cultura oral", e assenta um caráter contemporâneo, em que a "cultura escrita está superposta à oralidade como uma situação que governa as atividades normais da vida cotidiana". Contudo, Havelock permanece na defesa da preeminência da oralidade, argumentando, tese com que concordamos e asseguramos como mais indicativa de nosso estudo, que "o ser humano natural não é escritor ou leitor, mas falante e ouvinte" (1995, p. 27); e essa característica, nos afirma o autor, é biológica, portanto inegável. De acordo com Macedo (2004, p. 32), Havelock avoca que a prática da escrita se assemelha a um adestramento, por ser artificial e dependente do outro, do entorno, da cultura. Nas sociedades letradas, é uma condição imposta ao homem natural. A posição de Havelock não é compartilhada por muitos autores. Marcuschi (2003) defende a primazia da língua escrita, argumentando que sem escrita não haveria história, uma vez que a tradição oral tende a se perder, enquanto a escrita permite que a sociedade evolua e se constitua como existente, pelos registros que são deixados pela escrita. Daí a grande importância das descobertas arqueológicas, dos registros dos primeiros homens sobre a Terra.

Trazemos essa brevíssima discussão aqui tão somente para nos ampararmos, do ponto 
de vista metodológico, uma vez que, em pesquisas com histórias de vida, a oralidade é modalidade fundamental e indiscutivel fonte de informações. A Linguística há muito já vem alargando os seus grilhões para o reconhecimento dos estudos sobre a oralidade, com o progresso das pesquisas em sociolinguística, em análise de discurso, em análise da conversação etc. Hoje, com o avançar dos estudos sobre biografismos, a oralidade granjeia mais um ponto, em relação aos estudos sobre a escrita, e com uma vantagem: para os estudos biográficos, oralidade e escrita têm aproximadamente o mesmo prestígio.

Tendo sido nosso estudo amparado pelas duas modalidades - oralidade e escrita -, pautaremos agora nosso percurso para o trabalho investigativo-analítico, levando em conta que, para as histórias das crianças narradoras, a oralidade será substituída pela transcrição. Existem metodologias específicas de transcrição de textos orais, entretanto optamos por não seguir nenhum desses métodos, uma vez que não se trata de uma investigação estruturalista, em que pausas e tonalidades sejam relevantes. Trataremos de observar e desenvolver um construto acerca de como as crianças narradoras inserem-se em suas narrativas, a fim de refletir sobre a constituição e a permanência de um si em suas narrativas.

\section{Um estudo em três ciclos}

\section{Primeiro ciclo: sobre livros e filmes}

O primeiro ciclo do trabalho começou a ser realizado com crianças entre 8 e 12 anos, em tratamento contra o câncer, acolhidas na Casa de Apoio Lar Amigos de Jesus. Estas crianças vêm de diversos municípios do interior do Estado e ficam alojadas no Lar enquanto fazem os procedimentos em hospital-dia. A Casa foi fundada em 1987, ${ }^{4}$ com o objetivo de dar

4 Lar amigos de Jesus. Disponivel em: <www.laramigosdejesus.org.br/>. Acesso em: 10 ago. 2016. guarida a crianças e adolescentes, com suas respectivas famílias, no momento doloroso de seu tratamento médico-quimioterápico. Quanto à configuração da amostra, podemos afirmar que o grupo participante é muito variável e por esta razão decidimos abrir o leque etário e controlar somente a idade máxima de 12 anos. Na casa de apoio, não é possivel fixar um grupo devido à vulnerabilidade das crianças. Não é previsível o retorno de uma mesma criança à Casa e às vezes somos assomados pelo óbito de algumas delas. Desse modo, cada encontro realiza-se segundo o método fundamental de início e fechamento que desenvolvemos em nosso doutorado (MAIA-VASCONCELOS, 2003). Esse método consiste em nunca deixarmos atividades com as crianças para receber em outro dia. o que procuramos seguir como permanente é a idade limite e o número de crianças por grupo, a cada intervenção - 2 grupos de 4 a 6 crianças. Permanecemos sempre 60 minutos junto a cada grupo, um grupo por dia de intervenção, uma vez por semana. A aplicação desse método nos garante que sempre teremos um mesmo número de crianças (entre 4 e 6), em cada grupo amostral, independentemente da condição de saúde, fragilidade ou até mesmo de ter havido óbito ou cura de um dos indivíduos da amostra anterior. Todas as intervenções foram feitas na sala de aula ou na biblioteca da Casa de Apoio.

\section{Intervenções e metodologias dispostas}

Foram ofertados às crianças livros infantis diversos, além da projeção de filmes infantis, nas modalidades de desenhos animados, longa e curta-metragens, dentro da metodologia que será descrita na sequência. Foram realizadas filmagens, num total de 40 minutos de gravação, com as crianças em debate acerca do tema do filme projetado. Realizamos a gravação das crianças em debate; cerca de trinta 
minutos - 3 vídeos de 10 minutos cada - que foram transcritos e analisados.

Preliminarmente, pudemos intuir que a criança revela opiniões sobre os filmes e sobre as histórias contadas, de maneira a deixar perceber seu interesse ou desinteresse pelo tema. A aplicação dessa metodologia apresentou uma dificuldade adicional: esse momento de contato com as crianças foi o mais dificil de se realizar, pois 9 de cada 10 crianças alojadas na Casa de Apoio dispõem de aparelho celular e a casa dispõe de Internet wifi. Isso significa que todas estão conectadas, utilizando suas redes sociais.

Escolhemos para esta pesquisa a decisão de não interferir nessa atitude das crianças, não ter acesso a seus perfis em redes sociais, senão tentar convidá-las para participar de nosso trabalho. Devido a esse fato novo, consideramos que os 30 minutos gravados representam um grande passo na pesquisa, vez que a atenção dessas crianças é muito voltada para o celular e para a Internet. Para dar maior objetividade ao estudo, desconsideramos os minutos gravados em que não houve adesão das crianças ao trabalho proposto.

\section{O trabalho na Casa de Apoio - uma relação de confiança}

Para imergir no mundo dessas crianças, nós sabíamos que era necessário conquistar sua confiança. A convivência com esses sujeitos era muitíssimo atraente, escutar suas histórias era nosso objetivo, porém entrar em seus sonhos e conhecer profundamente suas experiências e seus sentimentos exigia uma relação de confiança, procedimento absolutamente indispensável ao nosso trabalho. Desse modo, a amizade ganhou lugar na pesquisa e este foi um bom caminho.

Acreditamos que estar em uma instituição para tratamento de doença grave e conviver com pares, em situação semelhante, permite ao sujeito enfermo ver sua situação um pouco como a dos demais. Apostamos na hipótese de que nesse momento acontece o que denominamos em estudo anterior (MAIA-VASCONCELOS, 2003), a partir das ideias de Lainé (1998), de recuo necessário à compreensão de sua história. Lainé (1998) trata do recuo histórico na sexta função narrativa, em que discute a decentração-objetivação das narrativas de vida. Pelos contatos, conversas, entrevistas, pelas construções discursivas, o sujeito pode formular uma nova maneira de ver sua própria história, a história de seus pares, o mundo, mesmo numa situação de doença grave e crônica. Como afirmou Pineau, ${ }^{5}$ em conferência sobre histórias de vida: o único tempo que podemos modificar é o passado. Nós jamais poderíamos alcançar esse íntimo lugar de suas vidas, sem um longo investimento na formação da relação de confiança. Conforme argumentamos em trabalho anterior, realizado junto a adolescentes com câncer:

Les rapports affectifs rendent plus aisés le discours narratif, les aveux ou confessions, les secrets personnels, et aussi l'intimité que le travail d'histoire de vie peut demander. Alors, les histoires se racontent dans le temps, chargées de souvenirs où se mêlent l'angoisse, la peur, l'espoir et finalement la certitude, ou l'incertitude. (MAIA-VASCONCELOS, 2010, p. 59) ${ }^{6}$

Após termos conquistado junto às crianças da Casa de Apoio Amigos de Jesus a ligação de confiança, foi feita uma primeira atividade de leitura, como previsto no projeto. À contação de histórias - na primeira experiência, a história de Chapeuzinho Vermelho - seguiu-se

5 Informação oral, durante a I Conferência Internacional sobre Histórias de Vida. Departamento de Letras Vernáculas, Universidade Federal do Ceará, 2010.

6 As relações afetivas tornam mais espontâneo o discurso narrativo, as confissões, os segredos pessoais e também a intimidade que o trabalho de história de vida pode demandar. Assim, as histórias vão sendo contadas através do tempo, carregadas de lembranças em que se misturam a angústia e o medo, a esperança e finalmente a certeza, ou a incerteza (MAIAVASCONCELOS, 2010, p. 59). 
a conversa em grupo, debate e refacção ${ }^{7}$ oral dos textos. As crianças mais velhas desinteressavam-se quando informávamos que seria lida a história de Chapeuzinho Vermelho, mas logo que começávamos a discutir alguns temas transversais, possiveis de serem inseridos na história, a participação voltava a aumentar. Fizemos intervenções sobre a infância (Chapeuzinho) e a velhice (vovozinha), sobre morar sozinho (vovozinha), sobre ter alguém que cuide de nós, sobre os perigos do mundo (Lobo Mau), a violência e a ação da polícia (Caçador). Houve grande adesão, inclusive dos adultos acompanhantes.

Debatemos com as crianças acerca das impressões visuais e não visuais que elas foram capazes de perceber e acerca daquelas provocadas pela intervenção do mediador. Houve um aglomerado de testemunhos sobre crianças que foram atacadas e até sequestradas de seus respectivos bairros, o que levou a criança a comparar o Lobo da história com o delinquente de sua vizinhança. Mas a polícia não consegue encontrar e salvar a criança, como o caçador o fez na história. Nesse momento, foram registradas as projeções que as crianças tiveram em relação a suas próprias experiências e às experiências de seus pares ou de pessoas de seu entorno. Essas informações foram de grande relevância para a confrontação com o texto de origem. Reações de choro foram comuns nesses momentos, como vimos em todo o estudo.

Para Bondioli e Mantovani (1998), quanto mais soubermos sobre a criança, quanto mais a conhecermos, mais seremos capazes de planejar atividades progressivamente estimulantes, promovendo uma aprendizagem complexa a acontecer de maneira natural e pertinente. A questão que os estudiosos se põem é saber

7 Embora Marcuschi (2001) e Matêncio (2003) considerem refacção sempre concernente ao texto escrito, optamos aqui por tratar a reconstrução textual oral como refacção. se a criança está apta a assumir uma responsabilidade enunciativa, um ponto de vista que seja dela mesma, e se este ponto de vista deterá uma autoridade diante do adulto. Não é dificil saber se a criança gosta ou não de um objeto ou de um filme, mas ter esta informação não significa ter conhecimento do que ela pensa sobre o fato de poder opinar, e talvez por essa razão pouco se dê ainda voz à criança. Daí por que resolvemos observar na pesquisa maior, não somente o que os adultos têm a dizer sobre o mundo infantil, incluindo nesse grupo de adultos nós mesmos durante a pesquisa, mas também procurar ouvi-la. A opinião de uma criança nos parece ser mais eivada de espontaneidade, o que nos distancia um tanto quanto da perspectiva bakhtiniana da auto-informe-confissão (BAKHTIN, 2003, p. 131) - categoria que considera a consciência valorativa do outro como princípio, uma vez que a forma da expressão e a própria linguagem, consideradas pelo russo como indispensáveis, nos chegam como transgressoras e sem preocupação estética. Para Bakhtin:

[...] nenhum reflexo sobre mim mesmo pode me concluir integralmente [...]; minha própria palavra sobre mim mesmo não pode ser essencialmente a última palavra, a que me conclui. [...] daí ser [a auto-informe-confissão] potencialmente infinito [...] um ato de incoincidência de si mesmo [...]. (BAKHTIN, 2003, p. 131).

Tal reflexão de Bakhtin nos permite reafirmar nossa tese de que o si é sempre como se fosse si. Assim como não podemos afirmar que a criança tem a consciência de poder opinar e tampouco sabemos o que ela pensa sobre esse poder, questionamo-nos sobre a consciência do adulto acerca do mesmo ponto. ${ }^{8}$ Sem admitir a ilusão biográfica de Bourdieu (1996), acreditamos que, ao narrar sobre si mesmo, o sujeito axiológico se põe em situa-

8 Apenas como provocação, cabe a reflexão sobre a célebre injunção jurídica: "exercerei meu direito de ficar calado". 
ção geonarrativa, oposta ao sujeito ontológico. A cada busca de si operada pelo sujeito, corresponde um apagamento de si que surge numa linha ondulatória teleológica que transforma todos os homens em um sujeito ôntico. Em outras palavras, defendo a tese de que não existe autobiografia no sentido estrito do termo, pois sempre que eu falo ou escrevo sobre mim, é um outro eu que se anuncia em meu espaço de escrita e reelabora um eu recriador e relator de uma história desse pseudoeu em que me transformo para falar de mim. Desse modo, o si é sempre uma farsa do si-mesmo, uma fantasia do si, uma máscara do que o sujeito pensa ser.

No que tange às narrativas de crianças, essa tese se fortalece, uma vez que ponderamos que o adulto, ao se narrar, pretende dar informações sobre sua vida, suas experiências, fazendo escolhas lexicais que oferecerão 0 matiz de sua narrativa. Ao passo que intuímos que a criança, por espontaneidade natural de sua idade, não planeja sua narrativa, no sentido de informar, ao interlocutor com quem está interagindo, detalhes minuciosos ou não sobre sua experiência de vida, sobre suas vivências individuais ou sociais. Ainda que fora da idade egocêntrica, a criança põe-se no centro das atenções, por entender que a história é dela, e se é dela, ela pode narrá-la como bem entende, sem se interessar pelo que o ouvinte irá entender.

Essas estratégias utilizadas pelas crianças, ainda que acreditemos serem manifestadas intuitivamente, foram observadas de perto na atividade na Casa. Fizemos a atividade com os filmes, como já relatado anteriormente neste documento, e obtivemos os seguintes resultados relativos à escolha do filme do dia que seria projetado no telão com data-show:

\begin{tabular}{|l|c|c|c|}
\hline Filme & 10 dia & 20 dia & 30 dia \\
\hline Homem Aranha & 17 & 21 & 23 \\
\hline Frozen & 27 & 25 & 15 \\
\hline Chapeuzinho Vermelho & 1 & 4 & 0 \\
\hline Peppa Pig & 20 & 12 & 11 \\
\hline
\end{tabular}

Em seguida, as crianças foram convidadas a elaborar predições sobre o texto/filme, a participar das atividades e a justificar suas predições. Neste momento, também se levou em consideração a socialização do grupo e se valorizou o eu e o outro e a construção do saber. A escolha do filme do dia promoveu, às vezes, algumas discussões e até aborrecimento entre os pares, mas, ao mesmo tempo, estimulou as crianças a recriarem um texto de forma livre, quando foi possivel incluir outros gêneros, como desenho, pintura, mímica, dramatização, jogos etc. A oralidade foi a principal estratégia de recriação utilizada pelas crianças participantes. A cada projeção, fazíamos as discussões antes e depois de projetar o filme escolhido. A escolha do filme, como já foi relatado, suscitava muitas vezes muita agitação, tumulto e até choro e desistência de alguns. Os conflitos gerados foram trabalhados como oportunidades de enfrentamento de problemas cotidianos.

Bowlby (1982) argumenta que a dificuldade em resolver um conflito se origina da "magnitude de seus componentes". Os impulsos conflitantes de uma criança estão sempre em 
relevo, em suas falas. O conceito de conflito elaborado por Bowlby (1982) nos assegura que esta é uma condição absolutamente corriqueira da vida, porque as mudanças ocorrem diariamente e toda e qualquer mudança exige novas adaptações. O conflito, ou a negação do conflito, pode estar associado ao que Bowlby (1982) chama mecanismos de defesa da pessoa, uma forma de evasão do conflito, que é definitivamente ineficaz. O conflito, para o autor, deve ser exposto em "campo aberto" e confrontado para ser visto em toda a profusão. Por esta razão, não interferimos diretamente nas decisões tomadas pelo grupo, salvo quando acreditávamos que o conflito se tornava desentendimento.

Nenhuma criança usou da doença com a finalidade de ganhar espaço, como chantagem emocional, o que nos surpreendeu de certo modo, pois esperávamos que as crianças usassem de sua fragilidade para nos convencer. Desse modo, a cada escolha, buscávamos conversar com todas as crianças, a fim de deixar esclarecido que qualquer que fosse o filme escolhido do dia, todos ganhariam, pois as projeções seriam feitas de todos os filmes, ainda que por meio da TV ou da tela do computador.

No momento final, entretanto, todos eram convidados a recontar a história inicial, a sua maneira, conforme thes foi possivel retextualizá-la. A observação das criações das crianças envolvidas na dinâmica pode propiciar a intuição da capacidade de expressão da criança, nas relações entre a história do outro e sua própria história (CRUZ, 2008).

Os conflitos gerados pela escolha do filme do dia foram, a nosso ver, naturais e esperados, uma vez que a criança se apodera com facilidade de sua opinião, como de um brinquedo que ela toma a brincar na escola e que em seguida sofre a ameaça de um coleguinha que lhe vem tomar o objeto já escolhido. As reações de agressividade, embora desaconse-
Iháveis em qualquer instância e tratadas como indevidas e desconstrutoras, são formadoras da personalidade da criança.

\section{Conclusões}

A reflexão advinda deste estudo, que ainda terá uma continuidade, diz respeito ao efeito de realidade e à reflexividade das crianças. Podemos dizer, até o momento, que os sinais de reflexividade que pudemos encontrar nas narrativas de crianças e de adultos não indicam uma existência estrita do si. As posições ocupadas pelos sujeitos em sociedade, a que denominamos de situações toponarrativas, não implicam necessariamente que haja uma singular narrativa de si, uma vez que este si nada mais é que uma imagem refletida/refratada daquilo que eu me considero ser na sociedade em que me insiro. Por conta das diversas máscaras que assumimos cotidianamente, somos múltiplos e nunca somos únicos. Estamos sempre numa relação de escrita e apagamento ontológico. Daí nossa consideração desse eu -outro, sempre presente, e que nos faz pensar que o si existe apenas como recurso linguístico de autoapresentação, como uma imagem do si que intentamos ser, mas que é sempre impossivel de materializar.

Desse modo, e como já defendemos, o si é sempre uma farsa do si-mesmo, uma fantasia do si, uma máscara do que o sujeito pensa ser. Nas narrativas de crianças, essa tese se fortalece, e oferece o tom de sua narrativa. Intuímos, em nossa pesquisa, que a criança é mais espontânea que o adulto, em sua narrativa, quando fala sobre suas vivências individuais ou sociais. Narrar-se não é escrever-se. Cada sujeito apresenta uma narrativa de si por meio da escrita/fala de si, mas nós não temos como desvelar esse sujeito pela narrativa que ele faz de si, senão pela escrita/fala narrativa que ele nos apresenta como sendo de si. Esse si é sempre um sujeito oculto cujas relações intra e in- 
terpessoais podem jamais se cruzar. Ressalto que esse "si" é sempre "como se fosse si". o professor que estiver atento a esta realidade obterá muito mais êxito no momento de sua prática de ensino de leitura no espaço da sala de aula.

Esses espaços inibidos pela desimportância do ser-aqui compreendido como a pessoa

\section{Referências}

BAKHTIN, M. Estética da criação verbal. Tradução de Paulo Bezerra. São Paulo: Martins Fontes, 2003.

BARTHES, R. 0 efeito de real. In: BARTHES, R. 0 rumor da língua. Tradução de Mario Laranjeira. Lisboa: Edições 70, 1984. p.131-136.

BERGSON, Henri. o que Aristóteles pensou sobre o lugar. Tradução de Anna Lia A. de Almeida Prado. Campinas: Editora da Unicamp, 2013.

BONDIOLI, A.; MANTOVANI, S. Manual de educação infantil de $\mathbf{0}$ a $\mathbf{3}$ anos. 9. ed. Porto Alegre: Artes Médicas, 1998.

BOURDIEU, Pierre. "A ilusão biográfica" In: AMADO, Janaína; FERREIRA, Marieta de Moraes (org.) Usos e abusos da história oral. Rio de Janeiro: Editora da FGV, 1996. p. 183-191.

BOWLBY, J. Formação e rompimento dos laços afetivos. Tradução de Álvaro Cabral. São Paulo: Martins Fontes, 1982. (The making and breaking of affections bonds, 1979)

CRUZ, C.; PEREIRA, C.; FERREIRA, C.; SANTOS, H.; RIBEIRO, M. Criança autista: pais e professores - uma parceria de sucesso no desenvolvimento de competências. Millenium, n. 39, p. 89-107, 2010.

CRUZ, S. H. V. Ouvindo crianças: considerações sobre o desejo de captar a perspectiva da criança acerca da sua experiência educativa. 27reuniao.anped.org. br. Cadernos de Pesquisa Fundação Carlos Chagas, v. 39, n. 139, p. 1-18, 2009. Disponivel em: <http:// www.publicacoes.fcc.org.br/ojs/index.php/cp/article/view/289/300>. Acesso em: 12 jan. 2016.

CRUZ. S. H. V. (Org.). A criança fala: a escuta de crian- em sua intimidade relacional com o mundo - propõe um conhecimento estéril de si que confrontamos como um nó a ser desfeito pela escrita biográfica. A narrativa de si exige um "si" a ser autodesvelado, autoconhecido e autorrelatado. Refiro-me ao sujeito inteiro, intuitivo, aquele que sabe, mesmo sem ter conhecimento.

ças em pesquisas. 1á. ed. 1a reimpressão. São Paulo: Cortez, 2008.

DILTHEY, W. Introdução às ciências humanas: tentativa de uma fundamentação para o estudo da sociedade e da história. Tradução de Marco Antônio Casanova. Rio de Janeiro: Forense Universitária, 2010a.

DILTHEY, W. A construção do mundo histórico nas ciências humanas. Tradução de Marco Casanova. São Paulo: Editora UNESP, 2010b. (Coleção Clássicos UNESP).

FRANÇOIS, F. Morale et mise en mots. Paris: L'Harmattan, 1994.

FRANÇOIS, F. Enfants et récits: mise en mots et "reste". Lille: Presses Universitaires du Septentrion, 2004.

FRANÇOIS, F.; HUDELOT, C.; SABEAU-JOUANNET, E. Conduites linguistiques chez le jeune enfant. Paris: PUF, 1984.

HAVELOCK. E. A. A equação oralidade - cultura escrita: uma fórmula para a mente moderna. In: OLSON, D. R.; TORRANCE, N. Cultura, escrita e oralidade. 2 ed. São Paulo: Ática, 1995. p. 141-161. (Coleção Múltiplas Escritas).

HEIDEGGER, M. Ser e tempo. Tradução de Maria Sá Cavalcante Schuback. 12. ed. Editora Vozes: Universidade São Francisco, 2002.

JONAS, H. Le principe de responsabilité: une éthique pour la civilisation technologique. Tradução de Jean Greisch, do título original: «Das Prinzip Verantwortung: Versuch einer Ethik fur die technologische Zivilisation (1979)». Paris: Les Éditions du Cerf, 1997. 
LAINÉ, A. Faire de sa vie une histoire: théories et pratiques de l'histoires de vie en formation. Paris: Desclée de Brouwer, 1998.

LUNA, J. C. O. História e pensamento hermenêutico na Alemanha do século XX. Revista Crítica Histórica, ano I, n. 1, p. 208-225, jun. 2010.

MACEDO, H. O. 0 processo de refacção textual na linguagem escrita de sujeitos afásicos. 2004. 227f. Tese (Doutorado em Linguística) - Universidade Estadual de Campinas, Instituto de Estudos da Linguagem, Campinas, SP, 2004.

MAIA-VASCONCELOS, S. Educação em âmbito hospitalar: o mito da descontinuidade. In: Encontro Nacional Sobre Atendimento Escolar Hospitalar, 1., 2000, Rio de Janeiro. Anais... Rio de Janeiro: UERJ, 2000. p. 35-47.

MAIA-VASCONCELOS, S. Penser l'école et la construction des savoirs: une étude menée auprès d'adolescents cancéreux. 2003. 500f. Tese (Doutorado em Sciences de l'Éducation) - Université de Nantes, Nantes, 2003.

MAIA-VASCONCELOS, S. Fazer-se autor em situação traumática na construção de um depoimento de si a partir do olhar sobre o outro. In: PASSEGGI, Maria da Conceição. (Org.). Tendências da pesquisa (auto) biográfica. São Paulo: Paulus; Natal: EDUFRN, 2008. v. 3. p. 231-247.

MAIA-VASCONCELOS, S. La clinique du discours dans la ronde des mots: parler pour se refaire la vie. Chemins de Formation, v. 12, p. 101-135, 2009.

MAIA-VASCONCELOS, S. Penser l'école et la construction des savoirs. Berlim: Editions Universitaires Européennes, 2010. v. 1. 454p.

MAIA-VASCONCELOS, S.; VASCONCELOS, Fabio Perdigão; FREITAS, M. L. T.; REBOUCAS, R. B. M. Estudo semiótico da paisagem: as histórias dos moradores da praia do Titãzinho (FORTALEZA/CE). Intersecções, Jundiaí, v. 3, p. 154-169, 2013.

MARCUSCHI, L. A. Da fala para a escrita: atividades de retextualização. 4. ed. São Paulo: Cortez, 2001.

MATÊNCIO, M. L. M. Referenciação e retextualização de textos acadêmicos: um estudo do resumo e da resenha. In: III Congresso Internacional da Abralin. Rio de Janeiro. Anais... Rio de Janeiro: Universidade Federal do Rio de Janeiro, Rio de Janeiro, 2003. p. 109-122.

MARTINS, A. F. A autoficção na literatura contemporânea (resumo expandido). In: Mostra De Pesquisa Da Pós-GraduaçÃo, 5., Porto Alegre. Anais... Porto Alegre: PUCRS, 2010. p. 848-850.

PASSEGGI, M. C. Pierre Bourdieu: da "ilusão" à "conversão" autobiográfica. Revista da FAEEBA - Educação e Contemporaneidade, Salvador, v. 23, n. 41, p. 223-235, jan./jun. 2014.

PASSEGGI, L. el al. A análise textual dos discursos: para uma teoria da produção co(n)textual de sentido. In: BENTES, A. C.; LEITE, M. Q. (Orgs.). Linguística de texto e análise da conversação: panorama de pesquisas no Brasil. São Paulo: Cortez, 2010. p. 262- 312.

PASSEGGI, M. C. (Org.). Tendências da pesquisa (auto)biográfica. São Paulo: Paulus; Natal: EDUFRN, 2008. v. 3.

PIAGET, J. 0 pensamento e a linguagem na criança. Tradução de Manuel Campos. São Paulo: Martins Fontes, 1999.

PINEAU, G. (Dir.). Accompagnements et histoires de vie. Paris: L'Harmattan, 1998.

PINEAU, G.; LE GRAND, J. L. Les histoires de vie. 2. ed. 8a mille. Paris: PUF, 1996.

RABATEL, A. 2008. Homo Narrans, pour une analyse énonciative et interactionnelle du récit. Limoges: Lambert-Lucas, 2008. (Coll. Linguistique). vol. 2.

RICOEUR, Paul. Temps et récit: l'intrigue et le récit historique. Paris: Éditions du Seuil, Tome I, 1991. (Collection Points Essais).

RICOEUR, Paul. Soi-même comme un autre. Paris: Seuil, 1990.

SÁ, R. N. de. As contribuições de Dilthey para uma fundamentação hermenêutica das ciências humanas. Boletim Interfaces da Psicologia da UFRuralRJ, p. 38-43. Disponivel em: <http://www.ufrri.br/seminariopsi/2009/boletim2009-1/novaes.pdf>. Acesso em 01 nov. 2016. 
SCHLEIERMACHER, F. D. E. Hermenêutica: arte e técnica da interpretação. Tradução de Celso Reni Braida. Petrópolis, RJ: Vozes, 1999.

SCHOPENHAUER, A. A arte de escrever. Tradução de Pedro Süssekind. Porto Alegre: L\&PM, 2009.

SIQUEIRA, K. A. Ortodoxia e heterodoxia nos relatos de mulheres vitimas de violência conjugal: amar a si mesmo como ao próximo. 2014. 167f. Tese (Dou- torado em Linguística) - Universidade Federal do Ceará, Fortaleza, 2014.

VYGOTSKY, Lev Semenovitch. Pensamento e Linguagem. Tradução de Jefferson Luiz Camargo. rev. téc. José Copolla Neto. 2a ed. São Paulo: Martins Fontes. 1998. (Tit. original Thought and language)

Recebido em: 18.09.2016

Aprovado em: 21.11.2016

Sandra Maia-Vasconcelos é professora associada do Departamento de Letras Vernáculas e do Programa de Pós-Graduação em Linguística de Universidade Federal do Ceará. Professora colaboradora do Mestrado Profissional em gestão de Negócios Turísticos da Universidade Estadual do Ceará. Bolsista Pós-Doutorado CNPQ. e-mail: sandramaiafv@gmail.com.

Rua Professor Sila Ribeiro, 340 - apto 501. CEP 60.175-135, Fortaleza, Ceará. 